\title{
A Psychometric Evaluation of the Threadgold Communication Tool for Persons with Dementia
}

\author{
Benedicte Sørensen Strøm a Knut Engedal c, d Ellen-Karine Grov b \\ a Center for Diakonia and Professional Practice, VID Specialized University, and b Oslo and \\ Akershus University College of Applied Sciences, Oslo, c Norwegian Advisory Unit for Aging \\ and Health, Vestfold Hospital HF, and d Department of Geriatrics, Oslo University Hospital, \\ Tønsberg, Norway
}

\author{
Key Words \\ Threadgold Communication Tool · Psychometric analysis - Principal component analysis . \\ Dementia · Elderly · Communication
}

\section{Abstract}

Background: The objective of this study was to investigate the psychometric properties of the Threadgold Communication Tool (TCT). Method: Internal consistency reliability was measured using Cronbach's $\alpha$ coefficient and inter-item correlation. Test-retest was performed to examine the instrument's stability. Exploratory principal component analysis (PCA) with oblimin rotation was carried out to evaluate construct validity. Finally, the score on each item of the TCT was correlated with the person's Mini Mental State Examination (MMSE) and Barthel Index of activities of daily living scores. Results: A total of 51 persons participated, with a mean age of 86.7 (SD 6.6) years, of whom 46 were women with moderate-to-severe dementia [mean MMSE score 7.5 (SD 6.7)]. There were two measurement points 2 weeks apart. The results showed a satisfactory level for internal consistency and a high test-retest reliability $(r=$ 0.76). The corrected item-total correlation ranged between 0.50 and 0.87 , and a two-factor structure was revealed at the PCA. 'Vocalizing' seemed to measure another aspect of communication and was the only item which was negatively loaded. Conclusion: Despite the low sample size in this study, the results revealed the TCT as a reliable and valid instrument, suitable for measuring communication among people with dementia. We suggest clarifying the understanding of 'vocalizing' before considering removing it from the scale. 
Strøm et al.: A Psychometric Evaluation of the Threadgold Communication Tool for Persons with Dementia

\section{Introduction}

Communication difficulties among people with dementia is a well-known problem and is one of the first symptoms of Alzheimer's disease. As the disease progresses, the ability to communicate is reduced [1], primarily the verbal communication [2].

In order to compensate for the lack of verbal communication, persons with dementia use non-verbal communication and behaviour to communicate in order to remain part of the communicative world [3] or to express their frustration and needs. However, the expressions might turn into agitation, aggression, irritability and repetitive vocalization [4-7] as well as into body movement, facial expression, touch, physical appearance, vocal communication [8], eye contact [9] or bodily conduct [10]. The frequencies of these symptoms increase with the severity of dementia [11], and the impairment might enhance the risk of misunderstanding, misinterpretation and consequent isolation [2].

Studies describe the challenges of trying to interpret the meaning of these different means of communication as well as finding non-verbal methods to maintain social contact with the person [12].

The sense of belonging and the wish to maintain social contact is a basic human need and does not change with dementia [13]. Prioritizing the relationship with the person with dementia to the same extent as the care tasks is one of the components of person-centred care [14]. This would include striving for mutual understanding [13 through different ways of communication. Establishing such contact can stimulate the senses and awaken latent memories which otherwise lie dormant [15].

Several tools to assess differentaspects of communication have been developed. However, most instruments focus on the persons' limitations and expressions such as agitation and aggression rather than on the capacity to communicate, verbally or non-verbally. Robert et al. [16] published a review in which they only found one scale that could be used to measure communication abilities in people with Alzheimer's disease: the Communication Problem Scale. This scale, as the title indicates, is focusing on limitations related to communication. Other scales, like the Cohen-Mansfield Agitation Inventory [17], only assess a few aspects of communication, mainly agitation.

Egan et al. [18] reported in a review that only a few studies have captured the communication interaction of people with dementia and suggest future studies should use tools that reflect a person's communication ability rather than his/her limitations. This is supported by a recent review where it states that limited attention has been given to the assessment of communicative abilities in people with dementia [19] despite the fact that 'communication becomes the crucial difference between isolation and social connectedness, between dependence and independence and between withdrawal and fulfilment' [20]. Having a standardized assessment tool for communication might help nurses to be able to respond to a person's need, despite language difficulties.

To our knowledge, only two dementia-specific communication tools have been developed: the Holden Communication Scale [21] and the Threadgold Communication Tool (TCT) [22]. Although none of these tools have been validated, the Holden Communication Scale has been used in some studies $[23,24]$, which is, however, not the case with the TCT.

We know that the progressive loss of the ability to perform activities of daily living (ADL) is often associated with a decline in cognition in people with dementia [25]. However, there is limited understanding of how the different aspects of communication might be affected by the ability to perform ADL and progression in cognitive decline. We, therefore, wanted to investigate if there is any association between the ability to communicate and the level of cognition and ADL, as measured by the Mini Mental State Examination (MMSE) and Barthel 
Strøm et al.: A Psychometric Evaluation of the Threadgold Communication Tool for Persons with Dementia

Index, respectively. However, the overall aim of this study is to investigate the psychometric properties of the English version of the TCT in a sample of persons with moderate-to-severe dementia living in nursing homes in Ireland.

\section{Methods}

The Sonas Programme is a multi-sensory stimulation programme developed by Sr. Mary Threadgold in Ireland in 1990 as a therapeutic activity for people with significant communication impairment, primarily as a result of dementia. It is based on Kitwood's idea of maximizing each person's potential which in this case is 'to activate whatever potential for communication has been retained by an older person with communication impairment' [22]. The programme involves cognitive, sensory and social stimulation, including all 5 senses: touch, smell, taste, hearing and sight. It is carried out in groups of 8, preferably twice a week for approximately $45 \mathrm{~min}$. The Sonas session is led by a Sonas Licenced Practitioner (SLP) with a 3 days' training regarding the concept of person-centred care as well as the different aspects of the programme and how to assess for communication ability using the TCT. The SLP is assisted by one member of staff during the session. Each participant is assessed by the SLP individually after each session, using the TCT.

\section{Sample and Procedure}

A convenience sample of 128 persons aged over 65 years living in 7 different nursing homes in Ireland were recruited to participate in a randomized controlled study. The recruitment process took place between January and March 2014. One of the inclusion criteria was the presence of moderate-to-severe dementia as classified by pre-trial MMSE scores of $0-20$. Persons who were in the palliative phase and not expected to live longer than 6 months, and those with major depression or severe pain were excluded. Fifty-six of the participants were randomly selected by the Director of Nursing in each nursing home for the intervention, reading and control group, respectively. The participants in the intervention group were supposed to attend the Sonas sessions twice a week for 24 weeks. There was a drop-out of 5 persons from the intervention group, and only the 51 participants who completed the intervention period have been included in this study.

The study was approved by the Regional Ethics Committee of Norway (REK) under the registration number IRB 0000 1870. No ethical approval was needed in Ireland, except from the board of management in each nursing home. Informed consent was obtained from the next of kin since the persons with dementia were unable to sign the informed consent form.

\section{Measures}

The demographic data were collected by the nurses from medical and nursing records, whereas ADL and cognitive levels were assessed at baseline by 1 nurse in each nursing home. The nurses were given training in advance by this article's first author.

Barthel ADL Index

The level of ADL functioning was assessed by the Barthel ADL Index. Each performance item is rated on the scale with a given number of points assigned to each level or ranking. There are 10 variables and a sum score where a high number is associated with a greater likelihood of being independent (possible top score is 100) [26]. 
Strøm et al:: A Psychometric Evaluation of the Threadgold Communication Tool for Persons with Dementia

Mini Mental State Examination

The level of cognitive performance was assessed by the MMSE. The questionnaire comprises 11 questions that cover orientation, memory, attention and calculation, recall, and language. Each question is scored, and the summing up leaves the possibility of 30 (highest sum score) [27].

Threadgold Communication Tool

The TCT is a proxy-based instrument designed to assess communication ability in persons with dementia after attending a Sonas Programme. The TCT consists of 14 items, and each item is graded from 0 to 4 , from no evidence to frequent evidence of communication [22]. The tool has been used extensively for the last 25 years in nursing homes in Ireland without being tested for reliability or validity.

Polit and Beck [28] recommend the period between baseline and test-retest assessment to be between 10 and 14 days. Based on this advice, we performed test-retest reliability by using the results of the first and fourth session. We expected no effect of the Sonas Programme after such a short period. The TCT was rated by the SLP, trained in accordance with the requirement stated by Sonas aPc [22].

\section{Statistical Analysis}

Data were analysed using the Statistical Programme for Social Sciences (SPSS), version 22.0. Descriptive characteristics of the participants were performed, and there were no missing values. The psychometric evaluation included internal consistency and construct validity.

Internal consistency reliability was analysed by Cronbach's $\alpha$ coefficient and corrected item-total correlation. The criterion level for acceptable reliability was set to $\alpha \geq 0.7$ [29]. Further, in order to discover if the items are measuring the same underlying characteristic, an inter-item correlation was performed.

The test-retest reliability was examined with a paired sample t test and intra-class correlation coefficient with a criterion level for acceptable set at $\geq 0.7$.

The suitability test of data for factor analysis was performed before the principal component analysis (PCA) based on Bartlett's test of sphericity (significance $>0.05$ ) and the Kaiser Meyer Olkin ( $>0.60$ ). Exploratory PCA was performed, including all 14 items of the TCT to explore the component structure and construct validity. The number of components retained for extraction was based on the Kaiser criterion (eigenvalue $\geq 1$ ) as well as on an inspection of the scree plot. All samples were initially explored using both orthogonal (varimax) and oblique (direct oblimin) rotation, showing no differences between the two methods. Based on the assumption that there was a correlation between the two components an oblique rotation (direct oblimin) was performed [30]. Loadings $>0.40$ were considered satisfactory.

The concurrent validity between the TCT, MMSE and Barthel ADL Index was examined using Spearman's $\rho$, as recommend by Pallant [31] based on this study's smaller sample.

We did not consider that there was any need to measure the inter-rater reliability since the same SLP in each of the 7 nursing homes scored the TCT after the first and fourth session.

\section{Results}

The sample consisted of 51 persons, mainly women (90.2\%), with a mean age of 86.7 (SD 6.6) years. The mean MMSE score was $7.49 \pm 6.60$, whereas the mean Barthel ADL Index score was $27.55 \pm 21.64$ (table 1 ). 
Table 1. Characteristics of persons $(n=51)$

\begin{tabular}{l|l}
\hline Dement Geriatr Cogn Disord Extra 2016;6:150-160 \\
\hline DOI: 10.1159/000444789 & $\begin{array}{l}\text { C } 2016 \text { The Author(s). Published by S. Karger AG, Basel } \\
\text { www.karger.com/dee }\end{array}$ \\
\hline
\end{tabular}

Strøm et al.: A Psychometric Evaluation of the Threadgold Communication Tool for Persons with Dementia

$\begin{array}{lc}\text { Gender } & \\ \text { Male } & 5(9.8) \\ \text { Female } & 46(90.2) \\ \text { Marital status } & \\ \quad \text { Single } & 16(31.4) \\ \text { Married } & 6(11.8) \\ \text { Widowed } & 28(54.9) \\ \quad \text { Divorced } & 1(2.0) \\ \text { Age, years } & 86.86 \pm 6.60 \\ \text { Barthel ADL Index score } & 27.55 \pm 21.64 \\ \text { MMSE score } & 7.49 \pm 6.67\end{array}$

Table 2. Item performance for the TCT $(n=51)$

\begin{tabular}{|c|c|c|c|c|c|}
\hline \multicolumn{2}{|c|}{ Items } & \multirow{2}{*}{$\begin{array}{l}\text { Mean } \\
2.71\end{array}$} & \multirow{2}{*}{$\begin{array}{l}\text { SD } \\
1.22\end{array}$} & \multirow{2}{*}{$\begin{array}{l}\text { Corrected item-total } \\
\text { correlation }\end{array}$} & \multirow{2}{*}{$\begin{array}{l}\text { Cronbach's } \alpha \text { if } \\
\text { item deleted }\end{array}$} \\
\hline 1 & Eye contact & & & & \\
\hline 2 & Smiling & 2.33 & 1.27 & 0.797 & 0.955 \\
\hline 3 & Singing & 2.31 & 1.39 & 0.808 & 0.955 \\
\hline 4 & Using gesture & 2.10 & 1.31 & 0.846 & 0.954 \\
\hline 5 & Holding gaze & 2.27 & 1.18 & 0.802 & 0.955 \\
\hline 7 & Vocalizing & 2.02 & 1.30 & 0.500 & 0.962 \\
\hline 8 & Speaking & 2.41 & 1.25 & 0.775 & 0.956 \\
\hline 6 & Following with gaze & 2.24 & 1.21 & 0.781 & 0.956 \\
\hline 9 & Appropriate touch & 2.22 & 1.27 & 0.667 & 0.958 \\
\hline 10 & Exercises & 2.06 & 1.30 & 0.859 & 0.954 \\
\hline 11 & Rhythmic movements & 2.04 & 1.31 & 0.824 & 0.955 \\
\hline 12 & Contribution & 2.04 & 1.41 & 0.830 & 0.955 \\
\hline 13 & Using instruments & 2.08 & 1.39 & 0.876 & 0.954 \\
\hline 14 & Interactive posture & 2.10 & 1.30 & 0.820 & 0.955 \\
\hline
\end{tabular}

\section{Internal Consistency}

Cronbach's $\alpha$ coefficient for the total score was good, i.e. 0.95. However, with such a high Cronbach's $\alpha$ coefficient, a correlation analysis including the 14 items in the TCT was performed. Several of the items had a Pearson's correlation coefficient $>0.800$ : using gesture and rhythmic movements ( $r=0.821)$, holding and following with gaze $(r=0.805)$, rhythmic movements and exercises ( $r=0.819)$, using instruments and rhythmic movements $(r=0.817)$, using instruments and contribution $(\mathrm{r}=0.808)$, and interactive posture and using gesture $(\mathrm{r}=0.813)$ (table 2). The correlation between holding gaze and eye contact was lower $(\mathrm{r}=$ $0.665)$. The score of the items in the TCT were normally distributed, with a mean around 2 , and SD between 1.18 and 1.41 .

The inter-item correlation matrices were all positive; however, one item, 'vocalization', scored $<0.3(0.25)$ and was therefore not considered to correlate with the total score. The corrected item-total correlation ranged between 0.50 and 0.87 , with a mean score of 0.77 (table 2).

\section{Test-Retest Reliability}

The result from the two time points did not differ significantly (paired sample t test, $\mathrm{p}=$ 0.220 ). The intra-class correlation between the two assessments was 0.86 . The TCT total mean score was 30.8 (SD 14.6) at baseline and 32.6 (SD 15.5) at retest (table 3). 
Table 3. Test-retest reliability measures for the TCT $(n=51)$

\begin{tabular}{rllll}
\hline Scale & & $\begin{array}{l}\text { Baseline test }(\mathrm{n}=51) \\
\text { mean (SD) }\end{array}$ & $\begin{array}{l}\text { 2-week retest }(\mathrm{n}=51) \\
\text { mean (SD) }\end{array}$ & $\mathrm{p}$ value \\
\hline 1 & Eye contact & $2.71(1.2)$ & $2.71(1.0)$ & 1.00 \\
2 & Smiling & $2.33(1.2)$ & $2.73(1.0)$ & 0.07 \\
3 & Singing & $2.31(1.3)$ & $2.35(1.4)$ & 0.88 \\
4 & Using gesture & $2.10(1.3)$ & $2.24(1.2)$ & 0.57 \\
5 & Holding gaze & $2.27(1.1)$ & $2.49(1.1)$ & 0.32 \\
6 & Following with gaze & $2.24(1.2)$ & $2.39(1.2)$ & 0.53 \\
7 & Vocalizing & $2.02(1.3)$ & $2.16(1.3)$ & 0.59 \\
8 & Speaking & $2.41(1.2)$ & $2.49(1.4)$ & 0.76 \\
9 & Appropriate touch & $2.22(1.2)$ & $2.49(1.2)$ & 0.26 \\
10 & Exercises & $2.06(1.3)$ & $2.35(1.3)$ & 0.26 \\
11 & Rhythmic movements & $2.04(1.3)$ & $2.02(1.3)$ & 0.94 \\
12 & Contribution & $2.04(1.4)$ & $1.94(1.6)$ & 0.74 \\
13 & Using instruments & $2.08(1.3)$ & $2.08(1.5)$ & 1.00 \\
14 & Interactive posture & $2.10(1.3)$ & $2.29(1.3)$ & 0.46 \\
\hline Total & score & $30.8(14.6)$ & $32.6(15.5)$ & 0.55 \\
\hline
\end{tabular}

\section{Principal Component Analysis}

The PCA revealed a two-component structure when the eigenvalue $\geq 1$ was used and the scree plot was inspected. As we had only 51 participants, we first examined the suitability for conducting a PCA of the TCT by inspection of the correlation matrix. Bartlett's test of sphericity reached statistical significance $(p=0.000)$, and the Kaiser Meyer Olkin was 0.91. Based on this, a PCA was found to be appropriate.

The first component consisted of the following items: eye contact, smiling, singing, using gesture, holding gaze, following with gaze, appropriate touch, exercises, rhythmic movements, contribution, using instruments and interactive posture. It had a Cronbach's $\alpha$ of 0.96 and accounted for $66 \%$ of the variance. The second factor consisted of two items, i.e. speaking and vocalizing, and had a Cronbach's $\alpha$ of 0.77 and accounted for $7.3 \%$ of the variance. The results of the rotated pattern matrix using oblimin rotation are shown in table 4. This twofactor solution corresponds to face validity of the TCT. However, when a PCA was performed, leaving 'vocalizing' out, it resulted in a one-factor structure, accounting for $69 \%$ of the variance.

Association between the Ability to Communicate and the Level of Cognition and Ability to Perform ADL

We found a moderate association between the total scores of the Barthel ADL Index ( $\rho=$ $0.418)$ and TCT and between the total score of MMSE $(\rho=0.484)$ and TCT. The ability to speak $(\rho=0.663)$ and do exercises $(\rho=0.628)$ seemed to be associated with the score on the MMSE. On the other hand, eye contact $(\rho=0.287)$, holding gaze $(\rho=0.355)$, being able to give appropriate touch $(\rho=0.331)$ and singing $(\rho=0.386)$ seemed to depend less on the outcome of the MMSE score. There was a relatively strong correlation between vocalizing $(\rho=0.470)$ and the ability to use an instrument ( $\rho=0.501$ ) and the total MMSE score. Regarding the ability to perform the ADL and the ability to communicate seemed to be slightly different. The correlation between ADL and ability for appropriate touch $(\rho=0.539)$, doing exercises $(\rho=0.522)$ and using instruments $(\rho=413)$ was quite high, whereas vocalizing $(\rho=0.191)$, singing $(\rho=$ $0.299)$ and following with gaze $(\rho=0.288)$ presented a small correlation with the outcome of the Barthel ADL Index (table 5). 
Dementia

and Geriatric

Table 4. Explanatory PCA with oblimin rotation of the 14 items of the TCT $(n=51)$

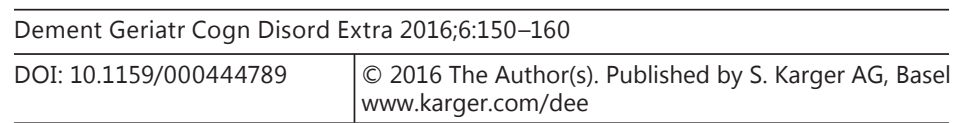

Strøm et al.: A Psychometric Evaluation of the Threadgold Communication Tool for Persons with Dementia

\begin{tabular}{cllc}
\hline Items & & Component 1 & Component 2 \\
\hline 1 & Eye contact & 0.859 & -0.273 \\
2 & Smiling & 0.797 & 0.073 \\
3 & Singing & 0.676 & 0.312 \\
4 & Using gesture & 0.864 & 0.040 \\
5 & Holding gaze & 0.854 & -0.021 \\
6 & Following with gaze & 0.931 & -0.189 \\
7 & Vocalizing & 0.076 & 0.877 \\
8 & Speaking & 0.525 & 0.529 \\
9 & Appropriate touch & 0.649 & 0.130 \\
10 & Exercises & 0.748 & 0.264 \\
11 & Rhythmic movements & 0.848 & 0.033 \\
12 & Contribution & 0.717 & 0.277 \\
13 & Using instruments & 0.859 & 0.094 \\
14 & Interactive posture & 0.902 & -0.072 \\
\hline Explained variance & $66 \%$ & $7.3 \%$ \\
\hline Cronbach's $\alpha$ & 0.96 & 0.77 \\
\hline
\end{tabular}

Table 5. Spearman's rank correlation between TCT and cognitive level and Barthel ADL Index and MMSE $(\mathrm{n}=51)$

\begin{tabular}{rlll}
\hline TCT & & Barthel ADL Index & MMSE \\
\hline 1 & Eye contact & 0.341 & 0.287 \\
2 & Smiling & 0.372 & 0.403 \\
3 & Singing & 0.299 & 0.386 \\
4 & Using gesture & 0.340 & 0.394 \\
5 & Holding gaze & 0.308 & 0.355 \\
6 & Following with gaze & 0.288 & 0.400 \\
7 & Vocalizing & 0.191 & 0.470 \\
8 & Speaking & 0.454 & 0.663 \\
9 & Appropriate touch & 0.539 & 0.331 \\
10 & Exercises & 0.522 & 0.628 \\
11 & Rhythmic movements & 0.371 & 0.418 \\
12 & Contribution & 0.355 & 0.443 \\
13 & Using instruments & 0.413 & 0.501 \\
14 & Interactive posture & 0.472 & 0.419 \\
\hline Total TCT & 0.418 & 0.484 \\
\hline
\end{tabular}

\section{Discussion}

To our knowledge, this is the first study to investigate the psychometric properties of the English version of the TCT in a sample of persons with moderate-to-severe dementia living in nursing homes in Ireland.

\section{Internal Consistency}

Cronbach's $\alpha$ coefficient for the total TCT was 0.95 , indicating a satisfactory level of internal consistency. However, such high Cronbach's $\alpha$ might indicate that some of the items are measuring the same. Holding gaze and following with gaze had a strong correlation $(\mathrm{r}=$ 0.805), which is not surprising. However, we would have expected holding gaze and eye contact to have an even stronger correlation than $r=0.665$, since these two concepts are considered to be the same. On the other hand, we did not expect using gesture and rhythmic 
Strøm et al.: A Psychometric Evaluation of the Threadgold Communication Tool for Persons with Dementia

movements to have such a strong correlation $(r=0.821)$ since these are very different forms of expressions: the first referring to facial gesture and the second more to use of body movement. The same might be argued for interactive posture and using gesture $(r=0.813)$, which also refer to two different ways of expressions.

As was expected, rhythmic movements and exercises $(r=0.819)$ as well as rhythmic movements and using instruments $(r=0.817)$ and using instruments and contribution $(r=$ 0.808 ) were found to have a strong correlation. However, rhythmic movements are considered as being able to move the body with the music and are therefore different from the ability to use an instrument, although both are closely connected. The ability to contribute to the Sonas session is only meant as the ability to join in proverbs and is therefore different from the use of instruments.

The inter-item correlation matrices were all positive, indicating that all items, except one, i.e. 'vocalizing', measure the same underlying characteristics [31]. 'Vocalization' scored $<0.3$ on the inter-item correlation matrix, which indicates that it is not measuring the same phenomenon as the other items. However, a corrected item-total correlation analysis showed a score between 0.50 and 0.87 , indicating that all 14 items are measuring the same, as the scale as a whole [31]. Cronbach's $\alpha$ was higher $(\alpha=96)$ when the item on 'vocalizing' was deleted from the analysis and loaded almost the same on both factors in the PCA. So, the question arises whether 'vocalization' could not only be an aspect of communication in people with severe dementia but a kind of agitation. Vocalizing has been considered a behavioural and psychological symptom of dementia (BPSD) by other authors, described as loud and/or repetitive communication, such as screaming, moaning, nonsensical sound and requests for attention [32]. However, Samuelsson and Hyden [33], in their study of the interactional pattern in persons with late-stage dementia, found the presence of a singing-like vocalization which was different from previously described non-verbal vocalization. Unlike former research, this suggested that non-verbal vocalization could have a social value and was not only just disruptive. Based on this understanding, it is important first of all that the understanding of vocalizing is clarified in the TCT before considering removing it from the scale.

\section{Test-Retest Reliability}

The result of the test-retest analyses revealed satisfactory values for the total score. There was stability between baseline and 2 weeks with no significance (paired sample t test, $p=0.220$ ), as well as for comparison between single items, indicating a good test-retest reliability. This shows that the assessments were carried out in a consistent way by the SLPs.

\section{Validity}

The factor analysis resulted in a two-component structure, explaining 73\% of the variance. All items loaded adequately, and the inter-item correlation matrix was all positive, indicating that items are measuring the same underlying communication characteristics. The items eye contact, smiling, singing, using gesture, holding gaze, following with gaze, appropriate touch, exercises, rhythmic movements, contribution, using instruments and interactive posture are considered as one component, describing non-verbal communication. We expected 'singing' to load on the dimension verbal communication. However, it did not, which is consistent with research reporting that persons with severe dementia and those who are not able to use verbal communication are still able to sing. Persons with dementia seem to have a preserved music memory despite the decline in language abilities [34].

Speaking and vocalizing described verbal communication representing the second dimension (component) (table 4). Despite the fact that 'speaking' loads highest on factor two $(0.529)$, it loads nearly as strongly on factor one (0.525). The challenge will then be where to best place this item. Moving it over to factor one would make us end up with only one item 
(vocalizing) on factor two. Although 'vocalizing' scores high on factor two, this is a questionable item. It seems to be more negatively loaded unlike the rest of the items in the TCT, and based on this, we suggest removing it from the scale. This suggestion might be strengthened by the findings, when performing PCA. When 'vocalizing' was left out, results revealed a onefactor structure. The fact that Cronbach's $\alpha$ increased after removing two items (factor 2) from the TCT might indicate that some other items are redundant as well, although we are aware that Cronbach's $\alpha$ depends on the number of items in a scale [30].

\section{Association between the Ability to Communicate and the Level of Cognition and Ability to}

Perform ADL

We found that some aspects of communication were associated with both cognitive level and ability to perform ADL. There was a low correlation between the total score of the TCT and MMSE $(\rho=0.484)$ and the Barthel ADL Index $(\rho=0.418)$, which indicates that the degree of cognitive decline and ADL has no strong correlation with the ability to communicate. However, when we look at the different aspects of communication, it is different.

The association between the ADL level and the ability to do exercises was strong ( $\rho=$ 0.522 ), which is quite obvious. Even though they might be able to perform physically in terms of exercises, following instructions may be difficult for persons with severe dementia, as this study indicates $(\rho=0.628)$. The same might explain why the ability to use instruments correlated strongly with the person's ability to perform ADL $(\rho=0.413)$ and the cognitive level $(\rho=$ 0.501) (table 5).

The cognitive level and the ability to speak and do exercises showed a strong correlation ( $\rho=0.663$ and 0.628 , respectively). This is consistent with previous studies, which report that the communication ability decreases with decline in cognition [18]. The case is different with 'singing', which was revealed to be less affected by the cognitive level $(\rho=0.386)$. Little is known about why the ability to sing is maintained longer in persons with dementia than the ability to speak. It was expected that 'vocalizing' showed a relative strong correlation with the cognitive level $(\rho=0.470)$. The assumption that 'vocalizing' is a form of BPSD is confirmed in a study by Selbaek et al. [11] where they found that as dementia progresses, the frequency in BPSD is increased.

Only eye contact demonstrates a small correlation $(\rho=0.287)$ with the cognitive level, which shows that the cognitive level does not seem to affect the ability to have eye contact. This is consistent with Sturm et al. [35] who examined mutual gaze during conversation and reported no relationship between gaze and cognitive level. However, the ability to hold gaze was documented to be slightly stronger $(\rho=0.355)$, even though they are used interchangeably.

Further, the correlation revealed that the ability to perform appropriate touch was more dependent on the person's physical status measured with the Barthel ADL Index $(\rho=0.539)$ than on the MMSE score $(\rho=0.331)$. This was as expected since appropriate touch requires a certain degree of movement and is less dependent on the person's cognitive level.

Since there are few 'dementia-specific' tools to assess the ability to communicate, removing the item 'use of instruments' might make the tool suitable in other situations. Examples of such situations could be related to personal care, meal situations as well as to different psychosocial interventions. This might be of importance for persons who are only able to use non-verbal communication since such information might help nurses to adjust daily care according to a person's communication behaviour. Such a positive approach, focussing on the person's opportunities to communicate instead of highlighting limitations, could improve the life of people with dementia. As for those who have difficulties expressing themselves verbally as part of the dementia process, this approach seems essential. Any efforts to create communication can help the nurses to get to know the person and their needs, as well as to prevent the persons with dementia from isolation. 
Strøm et al.: A Psychometric Evaluation of the Threadgold Communication Tool for Persons with Dementia

\section{Strengths and Limitations}

To our knowledge, there are no other available communication tools for persons with dementia which have been psychometrically tested. However, as there exists one other dementia-specific communication tool, the Holden Communication Scale [21], it would have been favourable if the TCT had been validated against this scale. The TCT mainly assesses the positive aspects of communication and, in that sense, is different from similar tools measuring negative aspects of communication. The relatively small number of participants $(n=51)$ compared to the number of items in the TCT is a clear limitation of this study. However, since the score of the items was normally distributed, with a mean score around 2 and no significant $\mathrm{p}$ values, we considered this dataset appropriate for the analysis performed. Another limitation might be that the TCT was only tested on persons with moderate-to-severe dementia and that the sample consisted mostly of female participants.

\section{Conclusion}

This study showed that there is a correlation between some aspects of the ability to communicate and the cognitive level among persons with dementia. An available psychometric tested instrument for persons with dementia will be a clinical advantage of verbal and non-verbal communication. Additionally, the use of an instrument like TCT could help nursing staff to detect the person's ability to communicate, which could improve the person's quality of life.

Despite the small sample size in this study, the results revealed that the TCT is a reliable and valid instrument, suitable for measuring communication among people with dementia. However, we suggest that an effort should be made to examine the way vocalization is understood in the TCT. We would consider removing this item from the scale unless it is given a clear positive expression following the rest of the tool's positive loading. Since some of the items seem to be redundant, a further reduction should be considered.

\section{Acknowledgement}

The authors would like to thank Sr. Morag Collins SJC for her detailed proof reading.

\section{Disclosure Statement}

The authors declare that they have no conflicts of interest.

\section{References}

1 Engedal K, Haugen PK, Brækhus A: Demens: fakta og utfordringer: en lærebok. Tønsberg, Aldring og Helse, 2005, p 423.

-2 Lykkeslet E, Gjengedal E, Skrondal T, Storjord M-B: Sensory stimulation - a way of creating mutual relations in dementia care. Int J Qual Stud Health Well-being 2014;9:23888.

-3 Hubbard G, Cook A, Tester S, Downs M: Beyond words: older people with dementia using and interpreting nonverbal behaviour. J Aging Stud 2002;16:155-167.

4 Bergh S, Engedal K, Røen I, Selbæk G: The course of neuropsychiatric symptoms in patients with dementia in Norwegian nursing homes. Int Psychogeriatr 2011;23:1231-1239.

5 Bergh S, Selbæk G: The prevalence and the course of neuropsychiatric symptoms in patients with dementia. Norsk Epidemiologi 2012;22:225-232. 
6 Selbaek G, Kirkevold O, Engedal K: The course of psychiatric and behavioral symptoms and the use of psychotropic medication in patients with dementia in Norwegian nursing homes - a 12-month follow-up study. Am J Geriatr Psychiatry 2008;16:528-536.

7 Selbæk G, Engedal K, Bergh S: The prevalence and course of neuropsychiatric symptoms in nursing home patients with dementia: a systematic review. J Am Med Dir Assoc 2013;14:161-169.

8 Argyle M, Dean J: Eye-contact, distance, and affiliation. Sociometry 1965;28:289-304.

-9 Clare L, Whitaker R, Quinn C, Jelley H, Hoare Z, Woods B, et al: AwareCare: development and validation of an observational measure of awareness in people with severe dementia. Neuropsychol Rehabil 2012;22:113133.

10 Kontos PC: Embodied selfhood in Alzheimer's disease: rethinking person-centred care. Dementia 2005;4: 553-570.

11 Selbaek G, Kirkevold 0, Engedal K: The prevalence of psychiatric symptoms and behavioural disturbances and the use of psychotropic drugs in Norwegian nursing homes. Int J Geriatr Psychiatry 2007;22:843-849.

12 Furusund AS: Signe som ikke ville dusje. Demens Alderspsykiatri 2007;11:19-22.

13 Edvardsson D, Winblad B, Sandman PO: Person-centred care of people with severe Alzheimer's disease: current status and ways forward. Lancet Neurol 2008;7:362-367.

14 Kitwood T: Dementia Reconsidered: The Person Comes First. Buckingham, Open University Press, 1997, vol $8, \mathrm{p} 160$.

15 Bakker R: Sensory loss, dementia, and environment. Generations 2003;27:46-51.

16 Robert P, Ferris S, Gauthier S, Ihl R, Winblad B, Tennigkeit F: Review of Alzheimer's disease scales: is there a need for a new multi-domain scale for therapy evaluation in medical practice? Alzheimers Res Ther 2010;2: $1-13$.

17 Cohen-Mansfield J, Marx MS, Rosenthal AS: A description of agitation in a nursing home. J Gerontol 1989; 44:M77-M84.

18 Egan M, Berube D, Racine G, Leonard C, Rochon E: Methods to enhance verbal communication between individuals with Alzheimer's disease and their formal and informal caregivers: a systematic review. Int J Alzheimers Dis 2010;2010:906818.

19 Strøm B, Ytrehus S, Grov E-K: Sensory stimulation for persons with dementia: a review of the literature. J Clin Nurs 2016, DOI: 10.1111/13169.

20 Beasley DS, Davis GA: Aging, Communication Processes and Disorders. New York, Grune \& Stratton, 1981.

21 Holden UP, Woods RT: Positive Approaches to Dementia Care. Edinburgh, Churchill Livingstone, 1995, p 225.

22 Sonas aPc. Sonas Workshop Booklet. 2011.

-23 Spector A, Thorgrimsen L, Woods B, Royan L, Davies S, Butterworth M, et al: Efficacy of an evidence-based cognitive stimulation therapy programme for people with dementia: randomised controlled trial. $\mathrm{Br} \mathrm{J}$ Psychiatry 2003;183:248-254.

24 Hutson C, Orrell M, Spector A, Dugmore 0: Sonas: a pilot study investigating the effectiveness of an intervention for people with moderate to severe dementia. Am J Alzheimers Dis Other Demen 2014;29:696-703.

25 Galasko D: An integrated approach to the management of Alzheimer's disease: assessing cognition, function and behaviour. Eur J Neurol 1998;5:S9-S17.

26 Shah S, Vanclay F, Cooper B: Improving the sensitivity of the Barthel Index for stroke rehabilitation. J Clin Epidemiol 1989;42:703-709.

$\checkmark 27$ Folstein MF, Folstein SE, McHugh PR: 'Mini-mental state'. A practical method for grading the cognitive state of patients for the clinician. J Psychiatr Res 1975;12:189-198.

28 Polit DF, Beck CT: Nursing Research: Generating and Assessing Evidence for Nursing Practice. Philadelphia, Wolters Kluwer Health/Lippincott Williams \& Wilkins, 2012.

29 Hardy MA, Bryman A: Handbook of Data Analysis. London, Sage Publications, 2004, vol 17, p 704.

30 Pett MA, Lackey NR, Sullivan JJ: Making Sense of Factor Analysis: The Use of Factor Analysis for Instrument Development in Health Care Research. Thousand Oaks, SAGE Publications, 2003.

31 Pallant J: SPSS Survival Manual: A Step By Step Guide to Data Analysis Using IBM SPSS. Maidenhead, McGrawHill, 2013, vol 14, p 354.

32 Yusupov A, Galvin JE: Vocalization in dementia: a case report and review of the literature. Case Rep Neurol 2014;6:126-133.

-33 Samuelsson C, Hyden LC: Intonational patterns of nonverbal vocalizations in people with dementia. Am J Alzheimers Dis Other Demen 2011;26:563-572.

34 Dassa A, Amir D: The role of singing familiar songs in encouraging conversation among people with middle to late stage Alzheimer's disease. J Music Ther 2014;51:131-153.

35 Sturm VE, McCarthy ME, Yun I, Madan A, Yuan JW, Holley SR, et al: Mutual gaze in Alzheimer's disease, frontotemporal and semantic dementia couples. Soc Cogn Affect Neurosci 2011;6:359-367. 